\title{
Conventional and Molecular Typing of Salmonella enterica serotype Typhi Locally Isolated In Baghdad
}

\author{
Ashna J.Faik* \\ Wafaa H. Salih ${ }^{* * *}$ \\ Received 20, December, 2010 \\ Accepted 11, March, 2012
}

Kawthar R. Latif ${ }^{* * * *}$

\begin{abstract}
:
Phenotypic And genotypic characteristics of Salmonella enterica serotype Typhi have been determined for 29 isolates, from Baghdad in 2007. Conventional typing methods were performed by biochemical tests, and antimicrobial susceptibility test. Molecular typing performed by analysis plasmid DNA beside using the Random Amplified Polymorphic DNA (RAPD-PCR). For the latter, two universal primers that have selected for the high discriminatory power were used for RAPD analysis. All isolates were belong one biotype according to the differention by their ability to decarboxylat lysine, 29(100\%) were lysine (+). All the isolates were susceptible to the Antibiotics used. However, all the strains free of plasmids. RAPD was capable of grouping the strains in 6 genotypic patterns using primer 784, in 4 genotypic patterns using primer 787. Conventional phenotypic typing methods, as well as the DNA plasmid analysis, presented non significant discriminatory power; however, RAPD-PCR analysis showed discriminatory power, reproducibility, easy interpretation and can be considered as a promising alternative typing method for $S$. Typhi.
\end{abstract}

\section{Keywords: Typing; Salmonella Typhi; Random Amplified Polymorphic DNA- Polymerase Chain Reaction;}

\section{Introduction:}

Salmonella enterica serotype Typhi is noteworthy in the etiology of outbreaks and sporadic cases of typhoid fever, which remains as an important public health problem, causing 16 to 17 million cases of the disease and about 600,000 deaths, annually, all over the world [1,2]. The investigation of the epidemiology of $S$. Typhi relevant, mainly in those areas where typhoid fever is endemic, resulting in a clear evaluation about the dissemination of strains and the establishment of prophylactic strategies. Molecular methods for characterization of $S$. Typhi strains have been developed and improved to complement conventional phenotypic -typing and allow the differentiation of non-related strains that belong to the same phage type, for example, multilocus enzyme electrophoresis [3], ribotyping [4], and pulsed field gel electrophoresis PFGE $[5,6]$. However, these techniques were all time consuming and technically demanding. A PCR-based typing method, RAPD-PCR (Random Amplified Polymorphic DNA), has been described as a simple and rapid method able to offer detailed fingerprinting of the genomic composition of the organism $[7,8]$ the success of this method is due to the fact that no prior sequence information about the target is needed and a single short 10-mer oligonucleotide primer can be used in the reaction. The amplification happens at low stringency, allowing the primers to anneal to several locations on the two strands of the DNA. These primers detect polymorphisms in the absence of specific sequence information and the DNA sequence variations may 
work as genetic markers that can be used in epidemiologic studies. Quintaes, et al. [9] have been demonstrated that RAPD-PCR reaction had the potential to provide a discriminatory, reproducible and easy to interpret method to type Salmonella enteric serovar Typhi strains. However, in order to use RAPD-PCR for differentiation between bacterial strains, the optimization of the reaction is imperative to eliminate most of the variations that are sometimes observed in duplicate DNA profiles [10]. Quintaes, et al. [11] reported and optimized of RAPD-PCR to Salmonella enterica serovar Typhi DNA using 10 mer oligonucleotide primer and demonstrate the effects in the fingerprint pattern caused by varying the target $\mathrm{DNA}, \mathrm{MgCl} 2$ and Taq DNA polymerase enzyme concentrations and the thermal cycling profile, also evaluate a total DNA extraction methodology, observing its time consumption and the stability of the resulting genetic material. In the present study the conventional system for typing Salmonella enterica serotype Typhi (biotyping, antimicrobial susceptibility) was evaluated and its performance compared to molecular typing methods (plasmid and RAPD-PCR analysis).

\section{Materials And Methods:}

Bacterial isolates

Salmonella Typhi isolates were obtained from blood samples (Table 1) and maintained in stock agar culture [12] at Central Public Health Laboratory(CPHL) Department of Bacteriology/ Enteric Diseases. The isolates were preliminarily grown in Brain Heart Infusion (Difco) for 24h at $37{ }^{\circ} \mathrm{C}$ Standard laboratory methods to isolate Salmonella ser. Typhi from blood samples were followed Bopp, et al.[13]. The conventional laboratory procedure involved culturing on
Kliglar's iron agar for fermentation and $\mathrm{H}_{2} \mathrm{~S}$ production, Urea agar for detection of urease, Simmon's citrate agar for detection of citrate utilization, semi solid mannitol for fermentation of mannitol and motility, peptone water for indol production and others ,the isolates were confirmed as $S$. Typhi by the biochemical characteristics and serotyped based on the Antigenic formulas of the Salmonella serovars Kuffman and White scheme was followed for serological confirmation and typing of Salmonella ser. Typhi by using Anti-Salmonella sera contain Salmonella: polyvalent O, polyvalent $\mathrm{H}$ Specific O-group: 9.12(D) and Vi Specific H: d prepared by Biomerieux laboratory. One drop of agglutinating sera of Salmonella Typhi was placed on a clean glass slide. One colony of test strain was picked up with a loop from a MacConkey's agar plate. The bacterial culture and agglutinating serum were mixed slowly with a sterile stick. When fully mixed the slide was rotated for 5-10 second. The agglutination was watched by naked eye. positive and negative controls were tested in similar way on the same slide. [13]. The bacteria were further investigated for biotyping. According to the classification proposed by The API 20E system which contains 20 different biochemical reaction including 10 enzymatic reactions, 10 fermentation oxidation reactions and an oxidas test was used. Susceptibilities to antimicrobial agents were determined by using the highpotency disk diffusion method [14]. The included antibiotics were ampicillin $(10 \mu \mathrm{g})$, ceftriaxone $(30 \mu \mathrm{g})$, ciprofloxacin $(5 \mu \mathrm{g})$, gentamicin (10 $\mu \mathrm{g})$, chloramphenicol (30 $\mu \mathrm{g})$, tetracycline $(30 \mu \mathrm{g})$ and trimethoprimsulfamethoxazole $(25 \mu \mathrm{g})$. Plasmid extraction All $S$. Typhi isolates were screened for plasmid content by the alkaline method Birnboim and Doly., 
1979 [15]. Electrophoresis of plasmid DNA was performed in $1 \mathrm{X}$ TBE at $7 \mathrm{v} / \mathrm{cm}$ for $1.5 \mathrm{~h}$ on $0.8 \%$ agarose gels, afterwards stained with ethidium bromide. Electrophoretic separation of plasmid species by molecular weight and subsequent size estimations using Lambda DNA/HindIII Markers (Promega, USA).

RAPD- PCR

The RAPD analysis was performed by Total DNA Extraction which was extracted from bacterial culture of $S$. Typhi using Wizard Genomic DNA Purification Kit, Promega (USA). The DNA was quantified, after electrophoresis in a $1 \%$ agarose gel. The RAPD-PCR Amplification was performed using two different primers according to the protocol of Quintaes et al. [9] . The sequence of primers were used, Primer 784 - 5'GCG GAA ATA G
3' and primer 787 - 5'AAC GCG CAA C $3^{\prime}$.The reaction was prepared using 50 $\mu \mathrm{l}$ per-tube, containing $20 \mathrm{ng}$ DNA of each isolates, 1 unit of Taq DNA polymerase enzyme (promega/USA), 1x PCR buffer, $2.0 \mathrm{mM} \mathrm{MgCl} 2,200 \mu \mathrm{M}$ of each dNTP, and 20 Pmol of primer. It was carried out in a thermal cycler programmed for 30 cycles composed of one step of denaturation for $1 \mathrm{~min}$ at 94 ${ }^{\circ} \mathrm{C}$, one step of annealing for $1 \mathrm{~min}$ at 36 ${ }^{\circ} \mathrm{C}$ followed by one step of synthesis for 2 min at $72{ }^{\circ} \mathrm{C}$. Amplification products were run on 1.5\%agarose gel electrophoresis followed by staining in ethidium bromide, and visualized by UV transilluminator. A negative control was included in each PCR run with no target DNA. The ladder $1 \mathrm{kbp}$ (Pomega/USA) were employed as molecular markers for bands weight.

Table(1): Phenotypic and genotypic characteristic of Salmonella serotype Typhi isolated in Baghdad

\begin{tabular}{|c|c|c|c|c|c|}
\hline isolates No. & Biotyping & Antibiogram & Plasmid & RAPD-PCR primer784 & RAPD-PCR prime 787 \\
\hline ST1 & I & A1 & - & R5 & D1 \\
\hline ST 2 & I & A1 & - & $\mathrm{R} 2$ & D1 \\
\hline ST 3 & I & A1 & - & R2 & D1 \\
\hline ST 4 & I & A1 & - & $\mathrm{R} 2$ & D2 \\
\hline ST 5 & I & A1 & - & R5 & D2 \\
\hline ST 6 & I & A1 & - & R5 & D1 \\
\hline ST 7 & I & A1 & - & R5 & D1 \\
\hline ST 8 & I & A1 & - & $\mathrm{R} 2$ & D1 \\
\hline ST 9 & I & A1 & - & $\mathrm{R} 2$ & D1 \\
\hline ST 10 & I & A1 & - & R5 & D1 \\
\hline ST 11 & I & A1 & - & $\mathrm{R} 4$ & D2 \\
\hline ST 12 & I & A1 & - & $\mathrm{R} 4$ & D3 \\
\hline ST 13 & I & A1 & - & $\mathrm{R} 4$ & D1 \\
\hline ST 14 & I & A1 & - & R2 & D4 \\
\hline ST 15 & I & A1 & - & R2 & D4 \\
\hline ST 16 & I & A1 & - & R2 & D4 \\
\hline ST 17 & I & A1 & - & $\mathrm{R} 2$ & D1 \\
\hline ST 18 & I & A1 & - & R5 & D1 \\
\hline ST 19 & I & A1 & - & R5 & D1 \\
\hline ST 20 & I & A1 & - & $\mathrm{R} 2$ & D1 \\
\hline ST 21 & I & A1 & - & $\mathrm{R} 1$ & D4 \\
\hline ST 22 & I & A1 & - & R6 & D4 \\
\hline ST 23 & I & A1 & - & $\mathrm{R} 2$ & D4 \\
\hline ST 24 & I & A1 & - & R3 & D1 \\
\hline ST 25 & I & A1 & - & R3 & D1 \\
\hline ST 26 & I & A1 & - & R2 & D3 \\
\hline ST 27 & I & A1 & - & R1 & D3 \\
\hline ST 28 & I & A1 & - & R4 & D1 \\
\hline ST 29 & I & A1 & - & R4 & D1 \\
\hline
\end{tabular}

ST: Salmonella serotype Typhi A: Antibiogram pattern D: RAPD-PCR Primer 787 pattern

R: RAPD-PCR Primer 784 pattern 


\section{Results :}

Based on biochemical findings one biotypes were observed (Table 1). They were differentiated by their ability to decarboxylat lysine. 29 isolates $(100 \%)$ were lysine $(+)$. Antimicrobial sensitivity test of all the twenty nine isolates were done. All the isolates were uniformly susceptible to the antibiotics used. Depending on the antibiotic sensitivity findings one antibiogram patterns were obtained. Plasmid DNA extraction from the isolates showed that all the isolates $29(100 \%)$ did not show any plasmid even analysis. Genetic differences among $S$. Typhi isolates were assessed by genomic fingerprinting obtained by RAPD-PCR using two different oligonucleutides primer. The amplifications with primer 784 divided the 29 analyzed strains into 6 distinct RAPD profiles (Fig. 1), revealing fragments ranging from 400 to 2500 bp. Fragments of $400 \mathrm{bp}$ are identical for all patterns except for pattern R3 where the 400bp band is absent. The profile R4 was prevalent in $41.37 \%$ of the strains (Table 1). Primer 787 divided the strains into 4 profiles (Fig. 2), showing less polymorphic bands patterns with fragments ranging from 400 to $2500 \mathrm{bp}$. Fragments of $600 \mathrm{bp}$ are identical for all patterns .The profile D1 was dominating (58.62\%) (Table 1).When the combination of amplification products patterns, generated by two primers were used to subtype $S$. Typhi strains, we found out a high diversity and it was possible to divide them into 10 distinct types.

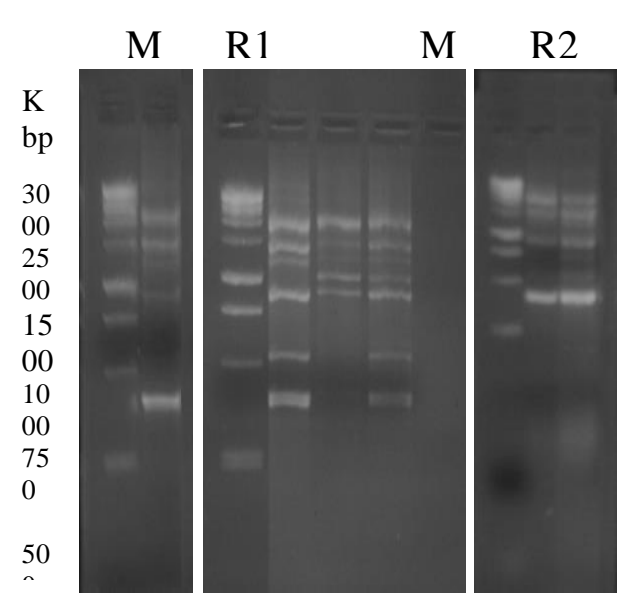

Fig 1.Representative profiles generated by RAPD-PCR using primer 784 lane:M. Marker $1 \mathrm{kbp}$ (Promega,USA) :1.RAPD profile R1: 2.RAPD profile R2: 3.RAPD profile R3: 4.RAPD profile R4: 5. RAPD profile R5: 6. RAPD profile R6. lane:N. negative control PCR products were separated on $1.5 \%$ agaros gel, $7 \mathrm{v} / \mathrm{cm}$, one hour electrophoresis.

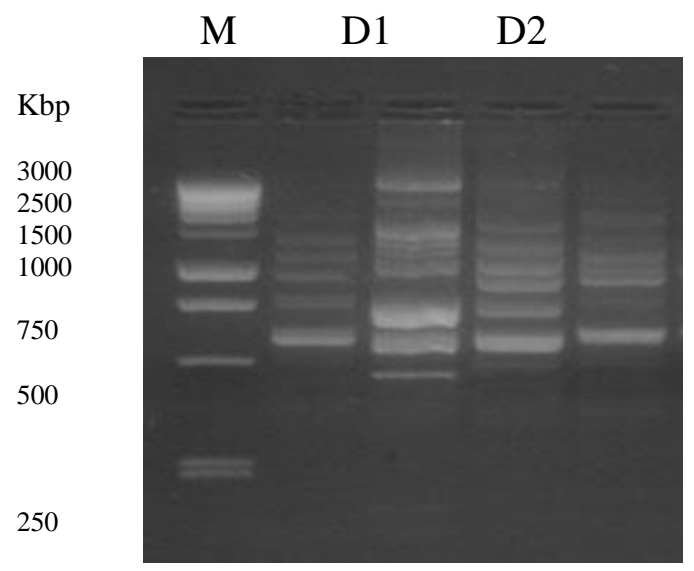

Fig 1.Representative profiles generated by RAPD-PCR using primer 787. lanes:M. Marker $1 \mathrm{kbp}$ (Promega,USA) :1.RAPD profile D1: 2.RAPD profile D2: 3.RAPD profile D3: 4.RAPD profile D4. Products were separated on $1.5 \%$ agaros gel, 7 $\mathrm{v} / \mathrm{cm}$, one hour electrophoresis.

\section{Discussion:}

The presence of $S$. Typhi in Iraq areas as a recurrent pathogen and as the cause of typhoid fever worldwide has determined the need to monitor the epidemic spread of this microorganism. The Kauffmann-White serotyping scheme is the traditional 
method for primary characterization of Salmonellae in the diagnostic setting [15]. While valuable for diagnosis and epidemiology, it is considered to be inappropriate for phylogenetic purposes [16]. Thus, it is necessary to explore a range of other techniques to establish genetic relationships among Salmonella serotypes [17] In this study, Biotyping, relying on the 20 biochemical reactions in API $20 \mathrm{E}$ system showed only one pattern of biochemical reactions (Table 1). Thus biotyping revealed a limited ability to differentiate between strains within a species and so has a poor discriminatory power. These results agreed with other researchers [9]. Antibiogram showed susceptibility to all antibiotics used (Table 1). This result is consistent with others researchers[9,18]. Based on antibiogram findings epidemiological analysis revealed that all isolates were indistinguishable, thus antibiotic susceptibility test was not reliable as an epidemiological marker for discrimination of $S$. Typhi in this study.Plasmid profiles proved not to be a good epidemiological marker for $S$. Typhi when analysing strains. The analysis of $S$. Typhi plasmids would be more suitable to characterize their temporal occurrence in an endemic setting and their possible association with the typhoid fever severity [19] as well as for analysis of outbreaks of nosocomial infections. Plasmid profiles are not very useful for subtyping $S$. Typhi since less than $10 \%$ of the strains, in general, harbor plasmids [20]. Indeed, we found that all of the strains were free of plasmid. This could be explained as a result of plasmid instability in $S$. Typhi, rather than an inherent barrier to the entry or establishment of foreign plasmid DNA. To interpret fragment patterns generated by RAPD-PCR, we should understand that the occurrence of random genetic events, including point mutation and insertions and deletions of DNA, can alter the RAPD fingerprinting patterns $[9,21]$. For this reason, we presumed the differentiating bands in the profiles could be due to one or more genetic events (Fig. 1 and 2 ). The discriminatory power of RAPD was tested by considering the number of profiles generated both with each primer separately, and combining the results obtained with the two primers (Table 1). When the RAPD profiles were analyzed considering the temporal occurrence, the prevalence of profiles R4 and D1 was evident. The traditional phenotypic typing methods used antibiogram typing and biotyping as well as plasmid profile, have low discriminatory power, while RAPDPCR proved capable of discriminating between $S$. Typhi strains [22] RAPDPCR assays are simpler, faster, more convenient and easier to perform low cost and potential to generate polymorphisms than most other molecular typing methods [21] .Our results suggest that there is a considerable possibility for increasing the efficiency of the RAPD-PCR reaction if a precise standardization protocol is determined. We have proposed a model that can be used as a support for typing strains of $S$. Typhi. AcknowledgementsWe thanks. Ali $\mathrm{H}$. AL-Wardy Director of Enteric Disease/Departmentofacteriology/CPH L/Baghdad for providing Salmonella enteric serotype Typhi isolates from Baghdad.

\section{References:}

1. Crump, J.A.; Luby, S. and Mintz, E. 2004. The global burden of typhoid disease. Bull. World Health Organization; 82:346-353.

2. WHO. 2005. Typhoid fever, Democratic Republic of the Congo. Wkly. Epidemiol. Rec. 80:1-8. 
3. Reeves, M.W.; E, G.M.; Heibar, A.A.; Plikaytis, B.D. and Farmer III, J. J. 1989. Clonal nature of Salmonella typhi and its genetic relatedness to other Salmonellae as shown by multilocus enzyme electrophoresis, and proposal of Salmonella bongori comb. nov. J. clin. Microbiol., 27: 313-320.

4. Ling JM, Loo NW, Ho YM, Kam KM, Hoa NT, Phi LT, and Cheng AF.2000. Molecular methods for the epidemiological typing of Salmonella enterica serotype Typhi from Hong Kong and Vietnam. J. Clin. Microbiol. 38:292-300.

5. Faik,A.J.2007.Molecular epidemiology analysis of Salmonella enterica serotype Typhi P.hD (thesis). College Of Medicine University of Al-Mustansiriya.

6. Kubota, K., T. J. Barrett, M. L. Ackers, P. S. Brachman, and E. D. Mintz. 2005. Analysis of Salmonella enterica serotype Typhi pulsed-field gel electrophoresis patterns associated with international travel. J. Clin. Microbiol. 43:1205-1209.

7. Tikoo, A.; Tripathi, A. K.;Verma, S. C.; Agrawal, N. and Nath,G.2001. Application of PCR fingerprinting techniques for identification and discrimination of Salmonella isolates. Curreent. Science. 80:1049-1052.

8. Betancor ,L., Schelotto,F., Martinez,A., Pereira,M. Algorta, G., Rodríguez, M. A., Vignoli,R., and Chabalgoity ,J.A. 2004.Random Amplified Polymorphic DNA and Phenotyping Analysis of Salmonella enterica Serovar Enteritidis Isolates Collected from Humans and Poultry in Uruguay from 1995 to 2002 . J. Clin.Microbiology.42:1155-1162.

9. Quintaes BR, Leal NC, Reis EMF, Fonseca EL, and Hofer E. 2002. Conventional and molecular typing of Salmonella Typhi strains from
Brazil. Revista do Instituto de Medicina Tropical de Sao Paulo 44: 315-319.

10. Yu K, Pauls KP.1996. Optimization of the PCR program for RAPD analysis. Nucleic Acids Research 20: 2606.

11. Quintaes, B. R.; Leal ,N. C. ; Reis ,E.M.F.; and Hofer, E. 2004. Optimization of randomly amplified polymorphic DNA-polymerase chain reaction for molecular typing of Salmonella enterica serovar Typhi da. Revista da Sociedade Brasileira de Medicina Tropical 37(2):143-147.

12. Sonnenwirth Alex; 1980:Gradwohls clinical Laboratory methods and Diagnosis, $8^{\text {th }}$ Edition, Vol 2, Mosby St. Louis.

13. Bopp, C.A.; Brenner, F.W.; Well, J.C. and Strockbine, N.C. 1999. Escherichia, Shigella, and Salmonella. In Manual of clinical microbiology, $7^{\text {th }}$ ed. Edited by Murray P. R.; Baron E. J. ; Pfaller M. A.; Tenover F. C., and Yolken R. H., American Society for Microbiology, Washington, D.C. Pp. 459.

14. Bauer A. W.; Kirby M. W., J. C. Sherris, and M. Turck. 1966. Antibiotic susceptibility testing by a standardized single disc method. Am. J. Clin. Pathol. 45:493-496.

15. Birnboim, H.C. and Doly, J.A. 1979. Rapid alkaline extraction procedure for screening recombinant plasmid DNA. Nucleic Acid Res. 7: 1513-1523.

16. Beltran, P., Musser, J. M.; Helmuth, R. ;Farmer J. J. ; Frerichs,W. M. ; Wachsmuth, I. K.; McWhorter, K. A. C.; Wells, J. G.; Cravioto, A. and Selander, R. K. 1988. Toward a population genetic analysis of Salmonella: genetic diversity and relationships among strains of serotypes $S$. choleraesuis, S.derby, S. dublin, S. enteritidis, S. 
heidelberg, S. infantis, S. newport, and S.typhimurium. Proc. Natl. Acad. Sci. USA. 85:7753-7757.

17. Baker,S., Holt,K., Vosse, E. Roumagnac, P., Whitehead, S., King,E., and Ewels, P. .2008. HighThroughput Genotyping of Salmonella enterica Serovar Typhi Allowing Geographical Assignment of Haplotypes and Pathotypes within an Urban District of Jakarta, Indonesia. J. Clin. Microbiol. 461741-1746 .

18. El-Ma'adhidi, A. H. A. R. 2004. Epidemiological and Molecular Study of AntibioticResistance of Some Salmonella species Isolated from Clinical and Non-Clinical Specimens. M.Sc. (thesis) Science in Biology / Microbiology College of Science University of Baghdad.

19. Finch, M.J.; Franco, A.; and Gotuzzo, E. 1992. Plasmids in Salmonella typhi in Lima, Peru, 1987-1988: epidemiology and lack of association with severity of illness or clinical complications. Amer. J. trop. Med. Hyg., 47: 390396.

20. Thong, K.L.; Puthucheary, S.; Yassin, R.M. 1995. Analysis of Salmonella typhi isolates from Southeast Asia by pulsed-field gel electrophoresis. J. clin. Microbiol., 33: 1938-1941.

21. Tenover, F.C.; Arbeit, R.D. and Goering, R.V. 1997. How to select and interpret molecular strain typing methods for epidemiological studies of bacterial infections: a review for healthcare epidemiologists. Molecular typing working group of the Society for Healthcare Epidemiology of America. Infect. Control Hosp. Epidem., 18: 426439.

22. Shangkuan $\mathrm{Y}-\mathrm{H}$, and Lin $\mathrm{H}-$ C.1998. Application of random amplified polymorphic DNA analysis to differentiate strains of Salmonella typhi and other Salmonella species. J. Appl. Microbio. 85: 693-702. 


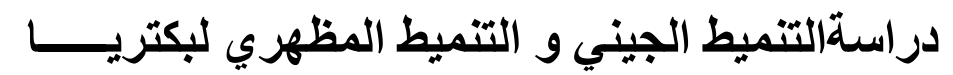

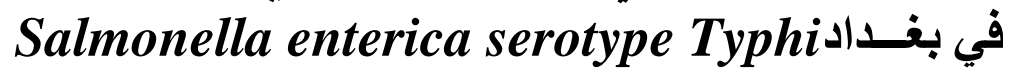

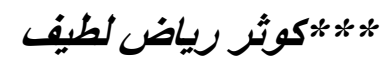 \\ \% \\ * : تشنا جمال فائق
}

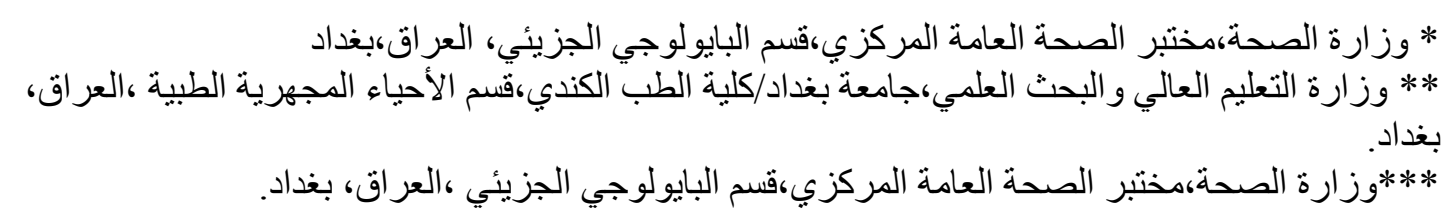

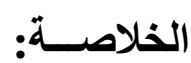

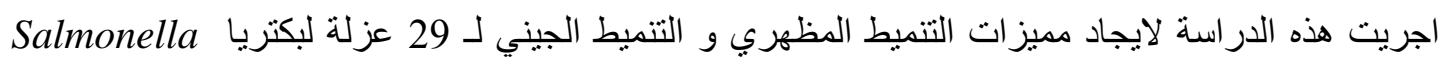
enterica serotype Typhi

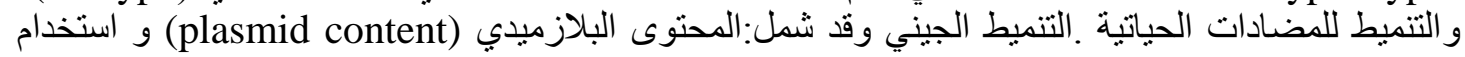

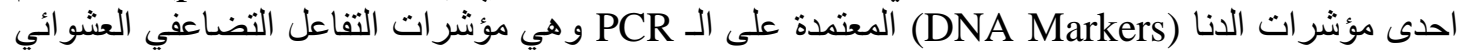

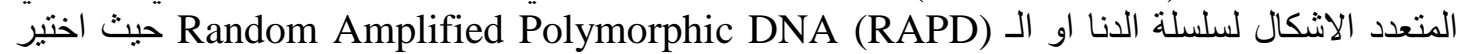

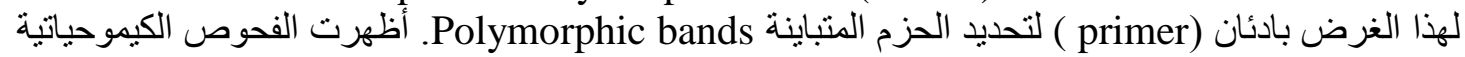

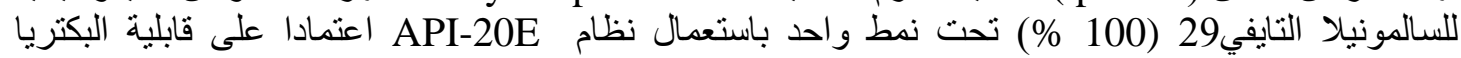

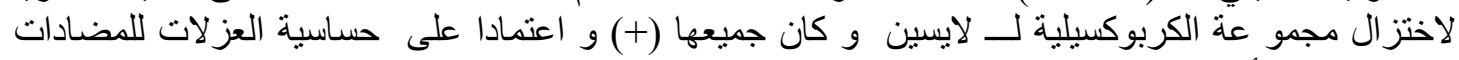

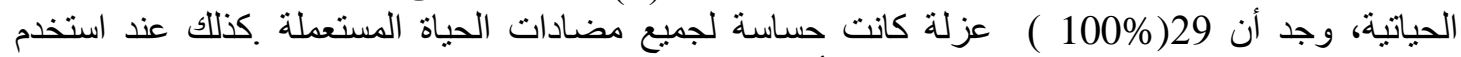

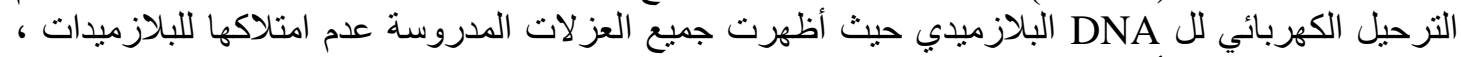

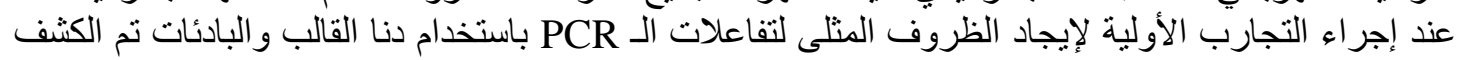

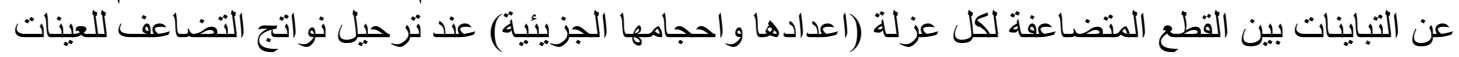

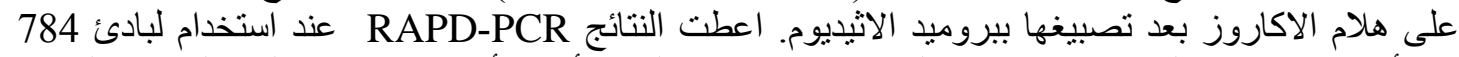

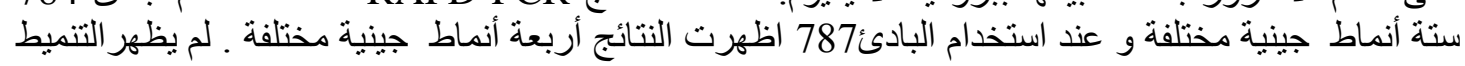

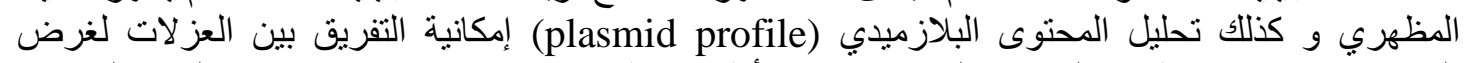

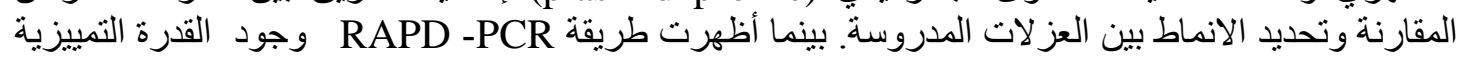

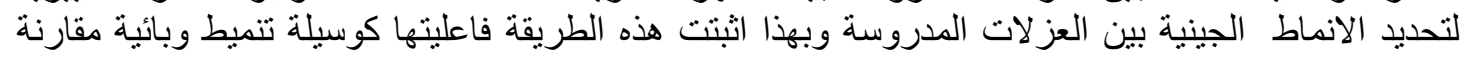

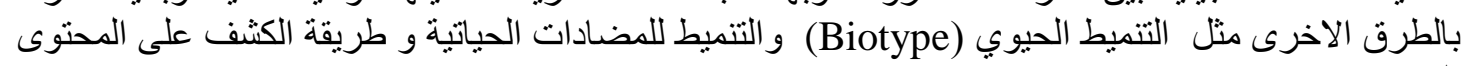
البلازميدي . 1الطرف الاخرى 